\title{
Research Paper: Explaining the Marital Adjustment Process in Iranian Women: A Grounded Theory Study
}

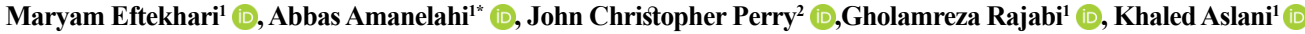 \\ 1. Department of Counselling, School of Education and Psychology, Shahid Chamran University of Ahvaz, Ahvaz, Iran \\ 2. Department of Psychiatry, School of Public Health, McGill University, Montreal, Quebec, Canada.
}

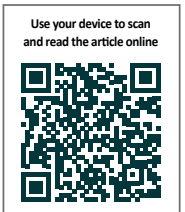

Citation Eftekhari M, Amanelahi A, Christopher Perry J, Rajabi Gh, Aslani Kh. Explaining the Marital Adjustment Process in Iranian Women. Journal of Research \& Health. 2021; 11(2):77-86. http://dx.doi.org/10.32598/JRH.11.2.1706.1

doi): http://dx.doi.org/10.32598/JRH.11.2.1706.1

\section{(1) (3)}

Article info:

Received: 16 Jul 2019

Accepted: 02 Jan 2020

Publish: 01 Apr 2021

\section{Keywords:}

Marital adjustment, Grounded theory, Traditional marriage

\section{ABSTRACT}

Background: Marital adjustment has a positive effect on the physical and mental health of family members. The purpose of this study was to explain the process of marital adjustment in Iranian women.

Methods: This research is based on qualitative data analysis using the grounded theory method Theoretical and purposeful sampling was used for data collection. Sampling continued until theoretical saturation. A total of 15 women from Ahvaz participated in the semi-structured interview. Interviews were analyzed using the Strauss and Corbin comparative method.

Results: By open coding, 17 primary codes, and axial coding, 9 major themes, related to marital adjustment were obtained. Marital adjustment: An incentive to maintain marital life were extracted as the central category influenced by contextual, causal, and confounding conditions. Contextual conditions include emotional bonding with parents and spouse. Causal conditions are an emphasis on self and relationship with another and how to express self in the relationship. Interfering conditions include a relationship with the main family, spouse, and social comparison. Strategies include defense mechanisms and empathy. The consequences of marital adjustment were also the sense of security and comfort.

Conclusion: Marital adjustment can be considered in curing marital maladjustment and conflicts and help therapists to have a better understanding of marital dynamics.

\section{Introduction}

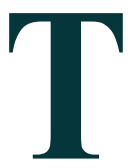

he marital adjustment has many consequences for the health of family members [1]. The lack of marital adjustment endangers marriage [2]. Marital adjustment is an evolutionary process in the relationship between couples that refers to a state of adjustment in different areas of the marriage where there may be con- flict. Understanding the individual characteristics of the spouse is an ongoing process in marriage because even if two people know each other before marriage or at the time of marriage, there is still the possibility of knowing new aspects of the opposite person. Therefore, marital adjustment requires maturity to be accepted and understood by the spouse. Unless such maturity is understood, death in marriage will be inevitable [3]. Many factors affect marital adjustment, one of which is the couple's

\section{"Corresponding Author:}

Abbas Amanelahi, $P h D$.

Address: Department of Counselling, School of Education and Psychology, Shahid Chamran University of Ahvaz, Ahvaz, Iran

Phone: +98 (916) 3008200

E-mail:a.amanelahi@scu.ac.ir 
personality. Accordingly, it calls for different types of reactions on the reciprocal side and subsequently, affects marital satisfaction and the degree of adaptation of couples [4-6]. Given the importance and role of marital adjustment, it is necessary to consider and evaluate this variable to increase marital satisfaction. Research on marital adjustment is scarce, and qualitative studies have examined marital success [7], marital relationship indicators [8], and stable marriage [9]. In particular, the concept of marital adjustment has been described and explained using the content analysis method that the accountability, understanding, communication structure, and conflict resolution have been introduced as the dimensions of marital adjustment. Qualitative studies, because of the observational approach, can examine indepth life experiences of individuals; thus, they will help discover the complexities of communication [10].

Because marital adjustment affects the mental and physical health of couples and their offspring, this study can be added to a series of scientific and intellectual research and discussions on marital adjustment that will hopefully bring about practical and practical outcomes in marital adjustment and subsequently, improve the mental and physical health of individuals. Therefore, due to the necessity of considering this variable and the lack of a qualitative model of marital adjustment, the present study was designed to fill the existing gap. Understanding the most important factors and how these factors affect marital adjustment, as well as understanding the process of acquiring marital adjustment were the goal of this study.

\section{Methods}

Due to the nature of the present study to explain the process of marital adjustment and because the researcher intended to explore the experiences and perspectives of individuals to formulate a theory and explain the process of marital adjustment, the grounded theory method was used. This study was performed on women living in Ahvaz using purposive sampling followed by theoretical sampling. In the first phase, the participants were selected purposively and included those informed about marital adjustment with an experience in this field. Theoretical sampling was performed in the next stage, and after the preliminary analysis, more participants were selected to refine emerging categories and theories. This process continued until the data saturation stage, where no new insights or ideas were obtained from the interviews. In order to attract the participants, the call for banners was installed in public places, and the women who responded positively and were eligible to enter the study were selected as participants. Inclusion criteria were women with higher education, the age of 20 to 50 years, first marriage, cases with 0 to 6 children, and lack of drug or substance abuse and 5 years have passed since their marriage. In this study, the data saturation criterion was used to determine the sample size. Interviews with 15 participants saturated the data. Semi-structured interviews were used to collect data.

Ethical issues in this study included obtaining informed consent from participants to participate in the research and video recording of the sessions, ensuring the confidentiality of the information and using the code for them, as well as the right to opt-out of the research. Also, calls for participation in the research in different locations of Ahvaz city were initially performed and several cases showed their willingness.

From those who met the inclusion criteria of this study and were interviewed, 15 individuals were selected through theoretical sampling according to the inclusion criteria. The interviews lasted for three months, May, June, and June 2018. All interviews were conducted at the Behavioral Sciences Research Center of the Shahid Chamran University of Ahvaz, which was determined during invitation and time designation, and this time was determined by the participants themselves. The duration of the interview varied 60-90 minutes. Before each interview, participants were informed that the content of the interview will be confidential and the entire interview was videotaped after obtaining their permission. The general question of the interview was that "from your point of view, what is the marital adjustment and how it can be achieved?" During the interview, each participant was free to express his views.

All recorded interviews were first transcribed and then analyzed. In this study, data were analyzed using the Strauss and Corbin model (1998), which included data coding in three stages: open coding, axial coding, and selective coding. Open coding is part of the analysis that specifically names and categorizes phenomena through careful examination of the data. It should be noted that the theoretical sampling at this stage is consistent with the axial coding objective. In axial coding, the categories were related to each other according to patterns (direct and indirect relationships). Next, selective coding was done, which is the process of systematically selecting the main category and linking it to other categories, validating relationships, and filling in the gaps with those that need further refinement [11]. In this study, after the interview, the members' accreditation method was used to reach the reliability criteria of the findings. Participants were asked to evaluate the overall findings and comment 
on their accuracy. Accordingly, the interviewee was provided with the primary and secondary codes of each interview and was asked to comment on the extent, to which the codes (researcher's perceptions) were consistent with what had been said. In most cases, the interviewees found the researchers' perceptions as primary and secondary codes to be close to their statements.

\section{Results}

Table 1 presents the demographic characteristics of the research participants.

At the end of the open and axial coding process, concepts and categories were extracted. By open coding 17 primary codes and axial coding, 9 major themes related to marital adjustment were obtained. The categories, subcategories, and open-source code are presented in Table 2:

Figure 1 illustrates the conceptual model of marital adjustment among the participants of this study, and also each category derived from this study:

Central category: Marital adjustment: An incentive to maintain marital life.

\section{Contextual conditions}

In this model, emotional bonding with parents and spouse as a causal factor influences marital adjustment.

\section{Emotional bond with parents and spouse}

Emotional bonding with parents and spouse are important factors in functioning as well as marital adjustment. In this study, two dimensions were identified: safe and unsafe. Participants have a secure bond, a sense of security and support from the family, and will have a trusting relationship with their spouse and express their feelings and desires verbally.

"We had arguments and fights in life, but this is not a reason for us to love or hate each other. The two sides are trying to understand each other's words and desires, and somehow struggle to keep their lives. I say sorry to my spouse. I say you did so I got mad at you. We do not say in the wrapper and the parody. I have kept silent for a while and frantically say what I want, but we can talk easily. We are very friendly. I depend on my mother. Thank God my mother wasn't bad. When I was complaining about my spouse and family, my mother would always calm me down" (age: 33 years, Bachelor's degree, freelance job).
On the other hand, insecure emotional bonding can lead to the fear of communication and expression emotions and fear of leaving or being rejected when discussing with a spouse, which can be seen as a precursor to the communication and anxiety of being angry with the spouse. It can foster a vicious cycle of fear of expressing emotions.

"Generally, I'm worried. my parents fought a lot, and I had to stay up in the morning so that my mother wouldn't kill herself'. This attachment style also shows its effects on marital life: "When I was having problems with her family, I didn't dare to say what I was sad about. I get angry too, he is angry and I have to take the lead. I try to make her not angry. I feel I need someone who can be a part of me sometimes and sometimes my husband doesn't provide this security" (age: 38, Master's degree, employee).

\section{Causal conditions}

Also, we identified factors that directly influenced marital adjustment, including emphasis on self and relationships with others, and how to express themselves in the relationship that will be elaborated.

\section{Emphasis on self and relationships with others}

The emphasis is on self and the factors of autonomy, independence, self-reliance, responsibility, achievement, and identity. Relationship with others also refers to interpersonal relationships and participation in social groups and readiness to experience warmth and intimacy and a sense of belonging. Too much emphasis on each of them forms two incompatible dimensions of dependency or need and self-blame. One participant said:

"I always wanted to prove to my dad that I had a good life". Elsewhere, the participant states that "If my guests come in, I will bother myself a lot (Refers to injured hand). There are other works. My spouse says you are very important to others. But it's true. I don't want to reject it that I want to be rational, to be lovely yeah"(age: 32 years, Bachelor's degree, housewife).

Another participant expressed the balance between relationship and self-definition:

"I am an independent person for myself. In my personal life, I don't think I need to have others. At the same time, I also respect my spouse very much. I try to persuade when there is disagreement. If I accept that convincing reason too" (age: 41 years, Master's degree, freelance job). 
Table 1. The demographic characteristics of the research participants

\begin{tabular}{|c|c|c|c|c|c|c|c|}
\hline Participant & Age & $\begin{array}{l}\text { Type of } \\
\text { Marriage }\end{array}$ & $\begin{array}{c}\text { Duration of } \\
\text { Marriage }\end{array}$ & $\begin{array}{l}\text { Number of } \\
\text { Children }\end{array}$ & Education & Job & $\begin{array}{l}\text { Have A Feeling of Marital } \\
\text { Adjustment in Marriage }\end{array}$ \\
\hline 1 & 27 & Traditional & 8 & 1 & Masters & Employee & Yes \\
\hline 2 & 26 & Traditional & 5 & 1 & Masters & Housewife & Yes \\
\hline 3 & 32 & Traditional & 9 & - & Masters & Housewife & Yes \\
\hline 4 & 30 & Traditional & 5 & - & PhD student & University student & Yes \\
\hline 5 & 30 & Traditional & 6 & - & PhD student & University student & Yes \\
\hline 6 & 42 & Traditional & 21 & 2 & Masters & Housewife & Yes \\
\hline 7 & 41 & Traditional & 23 & 2 & Masters & Freelance & Yes \\
\hline 8 & 38 & Traditional & 13 & 3 & Masters & Employee & Yes \\
\hline 9 & 57 & Traditional & 35 & 5 & Diploma & Employee & Yes \\
\hline 10 & 42 & Traditional & 15 & 2 & Associate degree & Employee & Yes \\
\hline 11 & 42 & Traditional & 18 & 3 & Masters & Employee & Yes \\
\hline 12 & 35 & Traditional & 11 & 2 & Masters & Employee & Yes \\
\hline 13 & 33 & Traditional & 8 & 1 & Masters & Freelance & Yes \\
\hline 14 & 25 & Traditional & 5 & 1 & Masters & Employee & Yes \\
\hline 15 & 25 & Traditional & 10 & 2 & Associate degree & Freelance & Yes \\
\hline
\end{tabular}

IPA:

Method of emotional-self expression in relationship

In this study, participants expressed their feelings, thoughts, and desires in two ways and each had implications for individual and marital life that will be explained in more detail. One way was the passive assertion, in which the person was unable to assert himself and passively allow others to easily ignore and violate rights and feelings. One participant said:

"That was a lot of pressure on me at the time. I study two disciplines at the same time, and from my main discipline, I still have failed. I was stuck because my brother told you it was right for you" (age: 25 years, Master's degree, freelance job).

Other participants also shared similar experiences:

"I had many wishes. I wanted to marry one of them. He seemed very honest, but my dad just said no because he didn't like his father and I accepted it very easily". "It was a week between suit and marriage, and it was a week that I realized I was getting married and then regretted it. Because of the supplies my mom and dad had seen, I didn't dare to bother me anymore, but I was sorry from day one" (age: 32 years, Bachelor's degree, housewife).

On the other hand, respecting the rights of others and recognizing the thoughts and feelings of others, and also using a clear, specific, and objective speech can protect personal rights and regulates and restrains the feelings in the relationship.

"I'm sorry to tell my spouse. I say you did so I got mad at you. We do not say in the wrapper and the parody. I am an independent person for myself. In my own life, I don't think I need to have anybody else. At the same time, I also respect my spouse very much. I try to persuade when there is disagreement. If so, I agree with that" (age, 38 years, Bachelor's degree, housewife).

Overall, decisive people view both positive and negative points in themselves and others fairly and emphasize the role of conversation in resolving more conflicts. 
Table 2. Categories, subcategories, and open-source codes related to marital adjustment

\begin{tabular}{|c|c|c|}
\hline Axial Coding & Open Coding & Conceptual Expressions \\
\hline $\begin{array}{l}\text { Emotional bond } \\
\text { with parents } \\
\text { and spouse }\end{array}$ & Insecurity & $\begin{array}{l}\text { Feeling of love despite the conflicting in life, being with the child as the father at the time } \\
\text { of selection } \\
\text { Problem-solving and expressing desires } \\
\text { The feeling of being supported by the family } \\
\text { Seeing the pros and cons of a spouse } \\
\text { Relationships based on trust and convenience in leaning against each other } \\
\text { Fear of losing mom } \\
\text { Lack of a sense of parental security } \\
\text { Support from someone other than parents } \\
\text { Parental disagreement with the choice of their child as a spouse } \\
\text { Lack of trust in a spouse } \\
\text { Fear of expressing your emotions } \\
\text { Lack of intimacy and security with your spouse } \\
\text { Need to have a backrest } \\
\text { Lack of safety and seeking it out of marriage } \\
\text { Fear of getting emotionally close to spouse and family }\end{array}$ \\
\hline $\begin{array}{l}\text { Emphasis on } \\
\text { self and } \\
\text { relationships } \\
\text { with others }\end{array}$ & $\begin{array}{c}\text { The balance between } \\
\text { emphasizing on self } \\
\text { and dealing with } \\
\text { others }\end{array}$ & $\begin{array}{l}\text { Asking others to solve their problems } \\
\text { Reaction based on the actions of others } \\
\text { Capacity to be more intimate with your spouse } \\
\text { Trying to get approval from others } \\
\text { Marital turmoil } \\
\text { Respecting the spouse and accept his/her opinion, while expressing the opinion } \\
\text { Making a balance the relationship between self-esteem and self-definition by working } \\
\text { and earning money } \\
\text { Being independent in personal life and intimate relationship with the spouse }\end{array}$ \\
\hline $\begin{array}{l}\text { Method of } \\
\text { Expression in } \\
\text { Relationship }\end{array}$ & Passive assertion & $\begin{array}{l}\text { Unable to respond appropriately on the occasion } \\
\text { Acting against desire } \\
\text { Avoiding Conflict } \\
\text { Avoiding dealing with others } \\
\text { No disagreement } \\
\text { Not expressing discomfort } \\
\text { Emphasis on dialogue in dealing with conflict } \\
\text { Regulation and control of emotions in the relationship } \\
\text { Clear and objective speech }\end{array}$ \\
\hline $\begin{array}{l}\text { Relationship } \\
\text { with main } \\
\text { family and } \\
\text { spouse }\end{array}$ & $\begin{array}{l}\text { Lack of fusion } \\
\text { Fusion }\end{array}$ & $\begin{array}{l}\text { Observing the boundaries of marriage } \\
\text { Ability to withstand emotions and not interfering with negative emotions in dealing with } \\
\text { a spouse } \\
\text { Thinking about the consequences of expressing negative emotions } \\
\text { Failure to adhere to the boundaries of marriage } \\
\text { Allowing others to comment on their marital life }\end{array}$ \\
\hline $\begin{array}{c}\text { Social } \\
\text { comparison }\end{array}$ & No comparing & $\begin{array}{l}\text { Avoid making comparisons by not openly discussing the lives of others at home when } \\
\text { financial problems are eroding } \\
\text { Having a sense of satisfaction in life } \\
\text { Comparison of the behaviors of a spouse with families of former suitors } \\
\text { Self-blame for self and others } \\
\text { Feeling uncomfortable }\end{array}$ \\
\hline $\begin{array}{l}\text { Marital adjust- } \\
\text { ment } \\
\text { "an incentive } \\
\text { to keep marital } \\
\text { life" }\end{array}$ & Negative compatibility & $\begin{array}{l}\text { Trying to stay committed to choices } \\
\text { Have an active role in raising children } \\
\text { Fear of divorce as a normal event } \\
\text { Fear of social isolation } \\
\text { Dependency on others and inability to meet their needs }\end{array}$ \\
\hline
\end{tabular}




\begin{tabular}{|c|c|c|}
\hline Axial Coding & Open Coding & Conceptual Expressions \\
\hline $\begin{array}{c}\text { Defense } \\
\text { mechanisms }\end{array}$ & Defense mechanisms & $\begin{array}{l}\text { Suppression } \\
\text { (Trying to ignore the problem and the emotions associated with it) } \\
\text { Passive aggression (eliciting abusive feelings in an indirect, covert, and irritating way to } \\
\text { others) } \\
\text { Projection } \\
\text { (denying his feelings, intentions, or experiences by attributing them to others) } \\
\text { Helplessness and passivity (taking the passive stance) } \\
\text { Outflow } \\
\text { (Describing uncontrolled behavior that occurred when feeling anger) } \\
\text { Blaming others (defense against emotional closeness and intimacy) } \\
\text { (Avoiding guilt by conveying unacceptable feelings to others). } \\
\text { Rationalization } \\
\text { (Inability to talk about your feelings without referring to a third party). } \\
\text { Sublimation (emotions can lead to activity). }\end{array}$ \\
\hline Empathy & $\begin{array}{l}\text { Putting herself in } \\
\text { place of others } \\
\text { Hesitate } \\
\text { Intimacy }\end{array}$ & $\begin{array}{l}\text { Putting self in place of spouse's mother and seeing the story through eyes } \\
\text { Pay attention to the emotional state of the spouse } \\
\text { Postpone speaking to another time } \\
\text { More intimacy }\end{array}$ \\
\hline $\begin{array}{l}\text { Feeling of safe } \\
\text { and secure }\end{array}$ & No worry & No worry about being accepted from spouse \\
\hline
\end{tabular}

URA

\section{Interfering conditions}

We identified factors that although could not directly affect the main phenomenon, could exacerbate or mitigate their effects on the main phenomenon. Interfering conditions include categories, such as the relationship with the main family, the spouse, and social comparison.

\section{Relationship with the main family and spouse}

Being dependent on the spouse may provide the basis for his/her involvement in the marital life. When couples experience a higher level of dependency, it can be a factor in incompatibility with those around them. In this regard, one participant stated:

"My sister-in-law is going into our issues and saying you couldn't make it because they didn't have good sex. My husband was hiding the smallest things from me. I don't want my sister's sister to get into my life but I can't. I don't think it interferes with compassion ... I calm down until I hear something that bothered me. For example, he hides something from me and someone calls and tells me the story. I'll tell her when my husband comes in and I'm empty. He always tells me that everybody says something you believe in" (age: 42 years, Bachelor's degree, employee).

On the other hand, not mixing with others preserves the boundaries of communication that can affect marital adjustment.
"I always listened to my husband's family when I was told, but I did my job and we never fought in the house because we could hear our voices and their interference doubled most of the conflicts in the park and others were unaware of them, even the family" (age: 30 years, $\mathrm{PhD}$. student).

\section{Social comparison}

Social comparison can lead to consequences, such as being happy and vulnerable to the emotions of such comparison. In this study, a social comparison one of the indirect factors affecting marital adjustment.

"One of the things that I didn't see in my spouse and I was very upset about was that the rest of my callers were very complimentary when they went in. For example, we were very happy to meet this family. My spouse doesn't look like me or anyone else" (age: 42 years, Master's degree, housewife).

On the other hand, one participant said:

"When we were financially pressured to see my friends go on such trips, I tried not to compare myself to them by reducing their relationships and less so. I was annoyed and more satisfied".

Despite the negative emotional consequences of comparison, such as guilt, self-blame, and blaming others, it can be used to manage threatened self-esteem. 


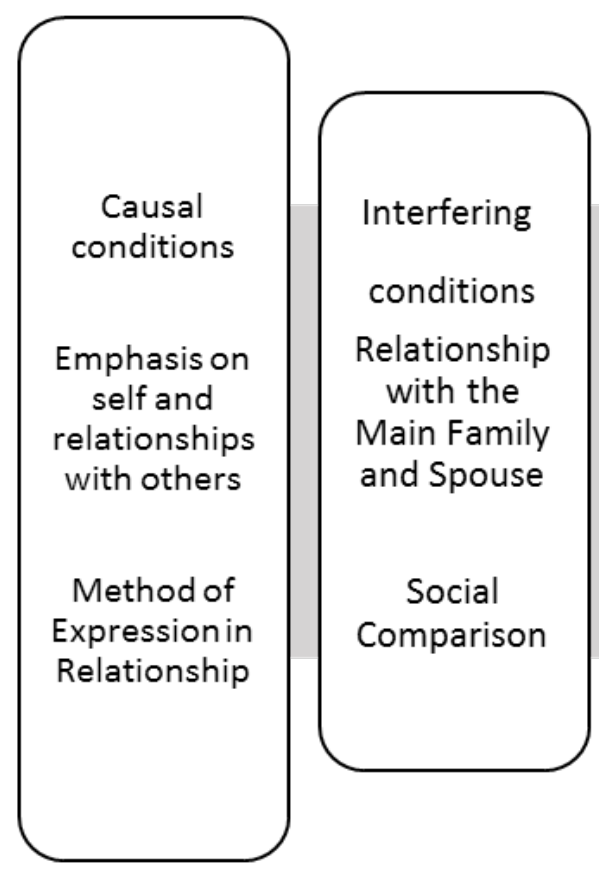

Figure 1. Conceptual model of marital adjustment

\section{Strategies}

In this study, participants discussed strategies they encountered in their marital lives and provided strategies to manage them, including defense and empathy.

\section{Defense mechanisms}

The use of various defense mechanisms was evident in the participants. These mechanisms included suppression, crying, somatization disorder, rationalization, passive aggression, projection, helplessness, inaction, acting out, blaming on others, rationalization, exaltation, denial, disintegration, self-destruction, and suppression. One participant said:

"I concluded that if you spend a lot of time laughing, it will work. Maybe the results I got in my life have proven to $m$ e" (age: 42 years, Bachelor's degree, employee).

People deal with emotional conflicts or internal or external stressors through extraversion and without overt or negative attention to their negative consequences. Extroversion involves expressing emotions, desires, or impulses as uncontrolled behavior with a clear disregard for personal and social consequences. Usually, this mechanism occurs in response to interpersonal events with important individuals in one's life, such as parents, significant others, friends, or loved ones [12].
One participant had used an extrinsic defense mechanism:

"When I conflict with my spouse, I release all the anger on my head. I feel like that I have to tell everything. I feel like my backpack. Sometimes I'm scared to show all my emotions to my spouse. I'm scared to be tired someday. I'll tell her everything. I even say I hate you" (age: 38 years, Master's degree, employee).

In contrast, some people use repressive defense mechanisms. Another participant said:

"I pour myself. I don't get it and I don't even let anyone know. Others do not understand my spouse does not care about a bored person, such as a child. Thinking more about desires" (age: 41 years, Master's degree, freelance job).

\section{Empathy}

Another strategy used to solve problems by participants was empathy. Empathy refers to putting yourself in the opposite position to experience the emotions and feelings of another person.

"My husband was also inexperienced", said one participant.

"It couldn't balance because he took mother's side. He said my mother says whatever you have to accept. I wouldn't accept either. The subconscious reaction was 
back in my life. But then I would say maybe everyone in my mother-in-law's place would do it with all the pressure" (age: 57 years, Diploma, employee).

Empathy also leads to increased communication and intimacy through compassion and caring for the spouse's needs, and these positive consequences reinforce empathy. One participant described her experience as follows:

"When I was in the early days of my marriage, my spouse wanted to talk with enthusiasm, and would tell me about own work. But when I saw my spouse tired and said nothing, I was disappointed. But now, I confess to myself that he is right and has had many customers since the morning and has no energy. I get to my spouse first, and after then gets up starts talking to me" (age: 38 years, Master's degree, employee).

\section{Consequences}

\section{The Feeling of Safety and security and comfort}

Feeling safe means there is no threat. People with a sense of security think of their performance positively, without the fear of any reason, and then experience a sense of peace and greater productivity than others. The sense of security is also categorized as a consequence. The participants stated that they had achieved a sense of security as a result of marital adjustment and that this was obtained by the acceptance of the spouse. One participant said:

"I never felt that my life was shaky. I never felt my spouse was going to leave or I was left alone. Maybe I'm not an ideal woman, but it's certainly accepted by my spouse. So it's good as it is" (age: 30 years, Ph.D. student).

The sense of calm means that the participating women had no particular concern about their marriage and are in a stable situation. Participants stated that they had achieved a sense of peace as a result of marital adjustment. The experience of this feeling arises when there is mutual trust in the spouse. In this regard, one participant said:

"When you have confidence in the opposite, you can solve your problems along the way. I am satisfied with the process myself and I am at ease in my life. Wherever my husband is, he will eventually come to his wife" (age: 30 years, $\mathrm{PhD}$. student).

\section{Discussion}

Couples who participated in this study believed that they had a marital adjustment. Although the participants had marital problems, they were able to achieve marital adjustment. Marital adjustment as a central category is influenced by a set of conditions and has implications for marital life.

According to this study, the causal conditions of marital adjustment are emphasis on self and relationship with others, and how to express yourself in the relationship. In this study, marital adjustment motivation to maintain a marital life was selected as the central category and was derived from two components of desire and fear. Accordingly, the desire to maintain a marital life by trying to stay focused on the choices and play an effective role in raising their children and on the other hand and the fear of divorce as an unusual event, followed by rejection by others and fear of being alone were mentioned by participants. Being dependent on others was identified as the obstacle to meet the needs. In brief, marital adjustment as a desire to maintain marital life means that one is looking for something that leads to positive experiences that can result in marital satisfaction and a sense of security and peace. While maintaining a marital life due to fear along with other factors can lead to negative marital adjustment.

The identified underlying condition for marital adjustment was emotional bonding with parents and spouse. The closest concept in psychology to this category is the attachment style that elicits a set of specific behavioral traits in individuals that affect their close relationships and emotional experiences and form the basis for forming intellectual and emotional interactions and frameworks that are observed during adolescence and adulthood. Therefore, it can be said that attachment is an individual variable that predicts satisfaction in romantic relationships. As the present study and other studies have shown, attachment style predicts marital adjustment, and the results of this study are in line with the findings of Besharat et al. [13] who reported that the relationship between parents during childhood and the quality of intimate relationships can predict marital adjustment in children. The results of this study also showed that the expression of feelings and emotions can influence marital adjustment by determining how to deal with conflict and feelings in the relationship, which is consistent with the results reported by Arefi et al. [14] and Sanagui et al. [15].

According to our results, the relationship with the main family and the spouse and social comparison were con- 
sidered as intervening factors in marital adjustment that provided the basis for maladjustment and interference. Using defense mechanisms, participants were able to respond to intrusive factors and reduce internal and external pressures. Accordingly, they responded to the situationusing defense mechanisms such as rationalization, passive aggression, projection and act out. In this regard, there was a difference between those with better marital adjustment and those with lower marital adjustment in terms of more mature defense mechanisms.

This study showed that couples use the strategies of defense mechanisms and empathy for marital adjustment. Defensive strategies used by couples can affect the marital relationship. Parents' defensive style before the birth of their first child was predictive of marital satisfaction at 4 and 12 months after birth. Developed defense mechanisms effectively dispel threatening emotions without distorting the perception of reality leading to constructive activity. However, underdeveloped defense mechanisms often involve distorting reality and cause inadequate performance. Underdeveloped defenses are common in children, but adults who continue to use undeveloped defensive styles experience greater psychological maladjustment [16]. Self-centeredness and the tendency to see issues solely on your own and neglecting the other's perspective are some of the sources of conflict and misunderstanding of the considered issue. Empathy is the sensitivity to accurately comprehend the thoughts and feelings that one experiences during communication [17]. This study showed that empathy leads to more intimacy and prevention of prejudicial attitudes and conflict and increased marital adjustment.

According to our findings, the consequences of marital adjustment are a sense of security and peace. Feeling safe means that there is no threat. People with a sense of security evaluate their performance positively, without the fear of any reason, and then experience a sense of peace and greater productivity than others. In this study, the feeling of security was considered as a consequence of marital adjustment. There was a positive significant relationship between marital adjustment and feeling of security and peace. If one considers his/her spouse's behavior responsive, he/she will feel more secure and more confident about his/her worthiness, but if one does not perceive his or her behavior as responsive, his or her sense of worth is reduced and this reduces communication security. In a successful marriage, the couple fully supports each other and feel secure [18]. Another study has shown that peace is the most important purpose of marriage. The family provides all the needs that are ex- pected to be met in the family and meeting the needs is associated with a sense of calm $[19,20]$.

Future research should examine marital adjustment in traditional and non-traditional marriages. This study was conducted on women that in order to gain a better understanding of the intrapersonal dynamics of each spouse and how these factors affect the relationship between couples, interviews with both people are suggested.

\section{Conclusion}

According to the present study results, marital adjustment is influenced by contextual, causal, and confounding conditions. Contextual conditions include emotional bonding with parents and spouse. Causal conditions are an emphasis on self and relationship with another and how to express self in the relationship. Interfering conditions include a relationship with the main family and spouse and social comparison. Strategies include defense mechanisms and empathy. The feelings of security and comfort were the consequences of marital adjustment. Thus, these issues can be considered in curing marital maladjustment and conflicts and help therapists to have a better understanding of marital dynamics.

\section{Ethical Considerations}

\section{Compliance with ethical guidelines}

This study was approved by the Ethics Committee of the University of Shahid Chamran Ahvaz (Ethical Code: EE/99.3.02.34465/scu.ac.ir).

\section{Funding}

This research did not receive any grant from funding agencies in the public, commercial, or non-profit sectors.

\section{Authors' contributions}

Study design: Maryam Eftekhari, Abbas Amanollahi, Gholamreza Rajabi, Khaled Aslani; Data collection and analysis: Maryam Eftekhari, John Christopher Perry, Abbas Amanollahi; Manuscript preparation: Maryam Eftekhari, John Christopher Perry.

\section{Conflict of interest}

The authors declared no conflict of interest. 


\section{References}

[1] Horwitz AV, White HR, Howell-WhiteS. Becoming married and mental health: A longitudinal study of a cohort of young adults. J Marriage Fam. 1996; 58(4):895-907. [DOI:10.2307/353978]

[2] Laurenceau JP, Stanley SM, Olmos-Gallo A, Baucom B, Markman HJ. Community-based prevention of marital dysfunction Multilevel modeling of a randomized effectiveness study. J Consult Clin Psychol. 2004; 72(6):933-43. [DOI:10.1037/0022006X.72.6.933] [PMID]

[3] Arshad M, Mohsin MN, Mahmood K. Marital adjustment and life satisfaction among early and late marriages. J Educ Pract. 2014; 5(17):83-90. https://www.iiste.org/Journals/index.php/ JEP/article/view/13913/14065

[4] Caughlin JP, Huston TL, Houts RM. How does personality matter in marriage? An examination of trait anxiety, interpersonal negativity, and marital satisfaction. J Pers Soc Psychol. 2000; 78(2):326-36. [DOI:10.1037/ /0022-3514.78.2.326] [PMID]

[5] Golparvar M, Taherizadeh J, Esmaili R. [Psychological-personality characteristics of maladjusted spouses and their marital adjustment in Iran and Toronto (Persian)]. J Fam Res. 2011; 7(2):22339. https://www.noormags.ir

[6] Attari YA, Amanellahi A, Mehrabizadeh M. The Relationship between personality characteristics and family personal factors with marital satisfaction among employees of government offices in Ahvaz (Persian)]. J Educ Psychol Sci. 2006; 3(13):81-108 https://www.sid.ir/fa/journal/ViewPaper.aspx?id=68289

[7] Asoodeh MH, Khalili S, Daneshpour M, Lavasani M GH. Factors of successful marriage: Accounts from self-described happy couples. Procedia Soc Behav Sci. 2010; 5:2042-6. [DOI:10.1016/j. sbspro.2010.07.410]

[8] Pirsaghi F, Zahrakar K, Kiyamanesh A, Mohsenzadeh F, Hassani J. [Effective marital relationship indicators: A qualitative study (Persian)]. J Consult Appl. 2018; 13:1-26.[DOI:10.22055/ jac.2017.22007.1464

[9] Hatami A, Esmaeily M, Farahbakhsh K, Borjali A. [Long term satisfied marriage model: A Grounded Theory study (Persian)]. J Family Counsel Psychother. 2016; 6(1):120-49. https:/ / www.sid. $\mathrm{ir} / \mathrm{fa} /$ journal/ViewPaper.aspx?id=315797

[10] Namvaran Germi K, Moradi A, Farzad V, Zahrakar K. [Identifying the dimensions of marital adjustment in iranian couples: A qualitative study (Persian)]. J Health Care. 2017; 19(3):182-94. http://hcjournal.arums.ac.ir/article-1-825-fa.html

[11] Corbin J, Strauss A, Strauss AL. Basics of qualitative research Techniques and procedures for developing grounded theory, $3^{\text {rd }}$ edition. Newbury Park, California: SAGE; 2015. https://www. amazon.com/Basics-Qualitative-Research-Techniques Procedures/dp/141290644X

[12] Perry JC, Kardos ME, Pagano CJ. The study of defenses in psychotherapy using the Defense Mechanism Rating Scales (DMRS). In: Hentschel U, Smith GJW, Ehlers W, Draguns JG, editors. The Concept of Defense Mechanisms in Contemporary Psychology. New York: Springer; 1993. https://doi.org/10.1007/978-1-46138303-1_8

[13] Besharat MA, Hoshmand SN, Rezazadeh SR, Lavasani M Gh [Predicting children's marital satisfaction in terms of parenting styles (Persian)]. J Rooyesh-e-Ravanshenasi. 2015; 4(3):51-60. http:/ / frooyesh.ir/article-1-110-fa.html
[14] Arefi M, Rahimi R, Sheikh Esmaeili D. [Predicting marital adjustment among young teaching couples on the basis of differentiation from the family of origin and parents' marital satisfaction (Persian)]. J Fam Res. 2016; 13(2):87-106. http:// qifr.ir/article-1-156-fa.html

[15] Sanagui M, Janbozorgi M, Mahdavian A. [Relationship between "marital satisfaction" and "communication patterns of couples" (Persian)]. Islamic Stud Psychol. 2011; 5(9):57-77. http://islamicpsy.rihu.ac.ir/article_1069.html

[16] Vaillant GE. Ego mechanisms of defense and personality psychopathology. J Abnorm Psychol. 1994; 103(1):44-50. [DOI:10.1037//0021-843X.103.1.44] [PMID]

[17] McDonald JE, Olson JR, Lanning AH, Goddard HW, Marshall JP. Effects of religiosity, forgiveness, and spousal empathy on marital adjustment. Marriage Fam Rev. 2018; 54(4):393-416. [DOI:10.1080/01494929.2017.1403992]

[18] Jafari Senejani M, Tiz Dast T, Farhangi A. Examining the relationship between psychological security, emotional maturity, and attachment styles and marital adjustment. Int J Med Res Health Sci. 2016; 5(9S):229-39. https:/ / www.ijmrhs.com/ abstract/examining-the-relationship-between-psychologicalsecurity-emotional-maturity-and-attachment-styles-andmarital-adjustmen-6634.html

[19] Lemay EP, Neal AM. Accurate and biased perceptions of responsive support predict well-being. Motiv Emot. 2014; 38(2):270-86. [DOI:10.1007/s11031-013-9381-2]

[20] Rowshani, S., Gharavi Naeeni, N., Bastani, S. [Women's experience of tranquility feeling in marital life: A qualitative study with grounded theory approach (Persian)]. Woman Fam Stud. 2016; 3(2):61-89. [DOI:10.22051/jwfs.2016.2208] 